\title{
Сом \\ Science created by crowds: a case study of science crowdfunding in Japan
}

\section{Yuko Ikkatai, Euan McKay and Hiromi M. Yokoyama}

\begin{abstract}
"Science crowdfunding" is a research funding system in which members of the public make small financial contributions towards a research project via the Internet. We compared the more common research process involving public research funding with science crowdfunding. In the former, academic-peer communities review the research carried out whereas the Crowd Community, an aggregation of backers, carries out this function in the latter. In this paper, we propose that science crowdfunding can be successfully used to generate "crowd-supported science" by means of this Crowd Community.
\end{abstract}

Keywords

DOI

Introduction
Citizen science; Science and media; Science communication: theory and models

https://doi.org/10.22323/2.17030206

\section{Trends in science crowdfunding}

"Science crowdfunding" is a way of carrying out research in which public supporters ("backers") make small financial contributions to a research project via the Internet [Wheat et al., 2013; Vachelard et al., 2016]. Recently, professional researchers have started to make increasing use of science crowdfunding [Byrnes et al., 2014; Hui, Greenberg and Gerber, 2014; Hui and Gerber, 2015]. The process of science crowdfunding is different from traditional public research funding in some points. In this study, we investigated how professional researchers and the general public recognize the process of science crowdfunding.

Most examples of science crowdfunding can be categorized as either reward-based or donation-based systems. Reward-based crowdfunding depends on the backers' financial support and generates returns. These returns are goods or services (e.g., T-shirts, mugs, mentions of the backers' names in a published paper) given to the backers by the researchers [Vachelard et al., 2016]. In contrast, there are no returns involved in donation-based crowdfunding, as the backers' financial contribution is considered to be solely in the form of a donation without returns. If the projects are labelled as tax-deductible, the backers can receive tax deductions for their donations.

When a professional researcher decides to start a project, they need choose a crowdfunding platform. This can be either (1) a "general-interest platform" that 
deals with various kinds of projects, including research, or (2) a "research platform" that specializes in research projects (Table 1). General-interest platforms are likely to be larger than research platforms. For example, on the world's largest general-interest platform, Kickstarter (U.S.A.), 136,520 funded projects (a total of 3,443,092,369 USD involving 14,015,122 backers) received support from 2009 to December 15, 2017. ${ }^{1}$ In comparison, on the world's largest research platform, Experiment.com (U.S.A.), 750 funded projects (a total of 7,614,262 USD involving 40,515 backers) received support from 2013 to December 15, 2017). ${ }^{2}$ In some universities, science crowdfunding campaigns are run on these platforms [e.g. Deakin University works with Pozible, Verhoeven and Astheimer, 2013].

Table 1. Examples of crowdfunding platforms.

\begin{tabular}{|lllll|}
\hline Category & \multicolumn{1}{c}{ Donation-based } & \multicolumn{2}{c|}{ Reward-based } \\
\hline \multirow{2}{*}{$\begin{array}{l}\text { General- } \\
\text { interest } \\
\text { platform }\end{array}$} & $\begin{array}{l}\text { JapanGiving } \\
\text { https://japangiving.jp/ }\end{array}$ & $\begin{array}{l}\text { (Japan) } \\
\text { Readyfor } \\
\text { https://readyfor.jp/ }\end{array}$ & $\begin{array}{l}\text { Pozible } \\
\text { https://pozible.com/ }\end{array}$ & (Australia) \\
\hline & $\begin{array}{l}\text { Experiment.com* } \\
\text { https://experiment.com/ }\end{array}$ & Readyfor & (Japan) \\
\cline { 2 - 5 } $\begin{array}{l}\text { Research } \\
\text { platform }\end{array}$ & & $\begin{array}{l}\text { Sciencestarter } \\
\text { https://www.startnext.com } \\
\text { /pages / sciencestarter }\end{array}$ & \\
\cline { 2 - 5 } & & & $\begin{array}{l}\text { academist }{ }^{\dagger} \\
\text { https://academist-cf.com/ }\end{array}$ & (Japan) \\
\hline
\end{tabular}

* Accepts applications from scientists (tenured faculty and independent researchers) and high school students.

${ }^{+}$Accepts applications from researchers (professional researchers affiliated with a university or research institute and independent researchers).

Some platforms only accept research project applications from professional researchers, while others are less strict in their definition of "researcher" and also accept applications from the general public. However, in this paper, we focused on professional researchers who were affiliated with a university or research institute and had the necessary qualifications to apply for public research funding. (Here, public research funding was considered to be based on a competitive funding system under the jurisdiction of a national government - quite different from any science crowdfunding system.)

In the process of science crowdfunding, the challenger (a professional researcher applying for funding) needs to carry out various tasks such as creating a project website and video materials to introduce their project, calling for support through social media and other channels, providing regular progress updates for backers via the website and social media, and replying to comments from backers [e.g., Dahlhausen et al., 2016; Schäfer et al., 2016; Vachelard et al., 2016]. Such tasks are not required (or at least not required to the same extent) in the normal public research funding process.

\footnotetext{
2018.

${ }^{1}$ Official webpage of Kickstarter, https:/ / www.kickstarter.com/help/stats, accessed on 1 January

${ }^{2}$ Official webpage of Experiment.com, https:/ / experiment.com/, accessed on 1 January 2018.
} 
In Japan, only a limited number of crowdfunded projects have been carried out, to date. The first project that drew public attention was the marathon-running challenge carried out by Prof. Shinya Yamanaka (director of the iPS cell research centre, CiRA, at Kyoto University). ${ }^{3}$ In March 2012, he took part in the Kyoto marathon as a charity runner, collecting donations for CiRA through the general-interest platform JustGiving (now known as JapanGiving). He raised 10 million Japanese yen (approximately 92,150 USD. All figures are given in February 2017 US dollars). In October 2012, he received the Nobel Prize in physiology and medicine. This greatly raised the profile of science crowdfunding as a means of raising research funds. In 2013, the first reward-based research platform, academist, [Shibato, 2015] was launched and professional Japanese researchers gradually started to make use of the platform. A total of 54 projects, ranging from 200,000 to 3.5 million Japanese yen (1,840 to 32,250 USD) had been funded by November 2017.4

Professional researchers can now choose from either research or general-interest platforms in Japan. In April 2016, the project team of Dr. Yousuke Kaifu (head of the National Museum of Nature and Science Department of Anthropology, Division of Human Evolution) raised 20 million Japanese yen (184,300 USD) on the general-interest platform Readyfor. ${ }^{5}$ This project aimed to investigate whether Japanese people originally came from Taiwan by recreating a boat journey using only the technology available 3,000 years ago. Not only professional researchers but also some adventurers were involved in this project. It featured on a TV program made by NHK, the Japanese national public broadcasting organization, and attracted widespread public attention. Due to this attention, the amount of money pledged by science crowdfunding for this project was one of the highest ever achieved in Japan at that time. A comprehensive survey focusing on the spread of science crowdfunding in Japan would be beneficial not only for future challengers but also to facilitate discussion about the impact of science crowdfunding on science in academia. However, such a study has not yet been conducted in Japan.

\section{Framework of this study: the peer review system and science crowdfunding}

In this article, we compare science crowdfunding with the basic framework used by the peer review system [Wellcome Trust, 2015], focusing on the importance of objectivity in science [Longino, 1990]. Here, the word "peer" usually refers to a professional researcher working in an academic field close to that of the reviewee [Iseda, 2017]. An academic article that successfully passes through the peer review process is generally considered to be reliable [Iseda, 2017]. The peer review system originated in the 18th century [Kronick, 1990] and became widespread by the late 20th century [Burnham, 1990]. It is used not only for articles published in journals but also for research proposals. In science technology and society (STS) studies, the question of what divides science from non-science has been much discussed

\footnotetext{
${ }^{3}$ Dr. Yamanaka awarded the Nobel prize. Thank you for your support (Kyoto marathon 2012) (in Japanese), https:/ /japangiving.jp/fundraisings/17882, accessed on 1 January 2018.

${ }^{4}$ Official webpage of academist, https: / / academist-cf.com/, accessed on 1 January 2018.

${ }^{5} \mathrm{~A}$ new challenge for the National Science Museum. An accurate recreation of a voyage that occurred 30,000 years ago (in Japanese). https:/ / readyfor.jp/projects/koukai, accessed on 29 May 2017.
} 
[Gieryn, 1994; Fujigaki, 2003]. Peer review is one of the systems that helps establish the boundary between science and non-science [Fujigaki, 2003]. In theory, mutual review by peers will eliminate any vague research hypotheses or questionable research findings. However, there is also a potential risk that the resultant article might be too conservative or that its evaluation might have been biased [House of Commons Science and Technology Committee, 2011].

In the public research funding process, two peer review stages can often be found. The first is when the research proposal is initially reviewed before budget allocation. Here, a professional researcher prepares and submits a research proposal to a government agency. The proposal is then peer reviewed by other researchers. In Japan, public research funding is based on a competitive funding system under the jurisdiction of the Ministry of Education, Culture, Sports, Science and Technology (MEXT) or other ministries. Grants-in-Aid for Scientific Research (called "KAKENHI" in Japanese) are a major source of competitive public research funding that covers the entire academic spectrum from science through to literature - overseen by the Japan Society for the Promotion of Science (JSPS), a subsidiary organization of MEXT. In 2017, the KAKENHI budget amounted to 2,284 billion Japanese yen (21 billion USD) and more than 70,000 research projects were supported. ${ }^{6}$ A KAKENHI proposal is first reviewed by peers and then a decision is made on whether the research project deserves funding. We propose the concept of a Budget-funding Community, consisting of peers that review the proposal, to describe this process.

The second peer review stage occurs when research results are published in a peer-reviewed journal. Especially in the natural sciences, the performance of researchers is evaluated mainly by their journal publication record. The normal peer review process involves an editor deciding whether the article is worth reviewing. The editor then selects suitable reviewers and asks them to take part in the process. The reviewers determine whether the article is worth publishing in specific journals and make their recommendations (e.g., major revision, minor revision, rejection) to the editor. The editor then makes the final decision, taking into consideration the comments made by the reviewers [Iseda, 2017]. Fujigaki [2003] proposed the concept of a Journal Community to describe this process, in which science is recognized as such through the publication of journal articles only after rigorous peer review. The determination made by the referees establishes a "validation boundary" separating science and non-science. This effectively means that the research published in a peer-reviewed journal has been approved as science (rather than pseudoscience) by the journal referees. In summary, the public research funding process involves two peer review steps involving both the Budget-funding Community and the Journal Community. This suggests that the academic value of the research is guaranteed by purely academic communities.

Science crowdfunding, on the other hand, lacks the peer review process carried out by the Budget-funding Community and the Journal Community, meaning that the academic value of the project is not solely guaranteed by academia [Weigmann, 2013]. At the initial stage of science crowdfunding, the backers individually decide whether the project is worth funding, without necessarily considering the specific details of the science involved. The way in which project results are communicated to the backers depends on the project. Some projects may publish their results in a

\footnotetext{
${ }^{6}$ Data of Grant-in-Aid for Scientific Research by the Japan Society for the Promotion of Science (in Japanese), https://www.jsps.go.jp/j-grantsinaid/27_kdata/, accessed on 1 January 2018.
} 
peer-reviewed journal, but others may not. In science crowdfunding, there is, therefore, less obligation to make the crowdfunded research results available through publishing in a peer-reviewed journal.

While platforms do not implement a peer review process analogous to that associated with public research funding, two general trends can be seen to be emerging. First, some academic platforms are introducing a peer review-like process as part of their screening [Weigmann, 2013]. For example, Experiment.com requires the endorsement of other researchers. ${ }^{7}$ Another example is the "gentle peer review process" implemented in research carried out by the platform RocketHub for \#SciFund challenge [Weigmann, 2013; Ranganathan, 2012]. These trends indicate that some platforms are starting to take account of the peer review process and are investigating possible alternatives.

In this article, we will discuss how we should consider the lack of a peer review system in most science crowdfunding and its positive or negative effects on science. We will address two fundamental research questions:

Research question 1: does the general public consider that the peer review process carried out by the Budget-funding Community is necessary in science crowdfunding?

Research question 2: do professional researchers who have participated in science crowdfunding consider that the peer review process carried out by the Budget-funding Community is necessary in science crowdfunding?

\section{Survey of the general public}

\section{Participants and questionnaire}

We conducted an online survey to investigate how members of the public view the process of science crowdfunding and the lack of a peer review process in Japan. This survey was conducted on August 23 and 24, 2016. The data were collected online by Macromill, Inc., a research company. We collected responses from 950 participants currently living in Japan. The age distribution of participants was selected to roughly match that of the over-20 population of Japan: 168 (male $=85$, female $=83)$ in their 20s, $225($ male $=114$, female $=111)$ in their 30s, $209($ male $=106$, female $=103)$ in their 40s, $203($ male $=101$, female $=102)$ in their 50s and 230 (male $=112$, female $=118$ ) in their $60 \mathrm{~s}$. All the responses were considered valid for statistical analysis.

The questionnaire contained two questions about the system of science crowdfunding (Q5-Q6, Figure 1). We asked the participants whether the current system is adequate or not. Since not all participants could be expected to be fully aware of the peer review system and science crowdfunding, the questionnaire included a diagram outlining the differences between the process of public research funding and science crowdfunding and a web article explaining science crowdfunding in Japanese. ${ }^{8}$

\footnotetext{
${ }^{7}$ Researcher guide of Experiment.com, https:/ / experiment.com/guide/extra\#trequesting_endorsements, accessed on 1 January 2018

${ }^{8}$ Can Japan's astronomy project team reach Hawaii? - A mystery that can generate 100 million yen but the team needs 800,000 yen in travel expenses, which they cannot afford (in Japanese), http:/ / bylines.news.yahoo.co.jp/ishiwatarireiji/20160516-00057712/, accessed on 7 December 2016.
} 
Lack of any peer review process in science crowdfunding: just under a third $(29.6 \%, n=306)$ of all participants responded that an expert peer review process is necessary in science crowdfunding (Q5 in Figure 1), 12.9\% $(n=133)$ called for recommendations to be submitted by other researchers, and $0.7 \%(\mathrm{n}=7)$ called for some other process, demonstrating an awareness of the need for peer review (or a similar process) to guarantee the quality of research results obtained by science crowdfunding. In contrast, $49.4 \%(\mathrm{n}=511)$ did not see any need for any peer review or similar process, and $7.5 \%(n=78)$ did not see any need for additional conditions to be placed on researchers (Q5 in Figure 1).

In addition, about $17.6 \%(\mathrm{n}=182)$ of participants responded that "publication in a peer-reviewed journal or book is necessary" (Q6 in Figure 1), suggesting that peer review (or a similar process) is required not only when applying for funding but also when presenting research results. Another 30.5\% $(n=316)$ of participants answered that researchers should provide progress reports for their backers, while $5.5 \%(n=57)$ said that no additional conditions were necessary, $0.4 \%(n=4)$ called for other options, and $46.0 \%(n=476)$ said that nothing was required of researchers (Q6 in Figure 1). Those results suggest that about 20 to 30\% of the general public consider that peer review or a similar system is desirable in the process of science crowdfunding.

\section{Survey of professional researchers who have applied for science crowdfunding}

\section{Participants and questionnaire}

We conducted an online survey of professional researchers who have applied for science crowdfunding in the past in order to investigate how they feel about the system of science crowdfunding. This survey targeted professional researchers who had pursued science crowdfunding as a means of raising research funding through three Japanese platforms: academist (research platform), Readyfor (general-interest platform), and JapanGiving (general-interest platform). We chose academist as it is the only research platform in Japan, Readyfor as it had delivered the maximum amount of science crowdfunding (184,300 USD for Dr. Kaifu), and JapanGiving as it had first attracted public attention to science crowdfunding (by supporting Prof. Yamanaka). The authors contacted the participating researchers by email or through Facebook and collected anonymous responses to an online questionnaire about science crowdfunding via Google. The deadline for responses was 12 days after sending participants the link to the online questionnaire.

Research-interest platform (academist): we targeted all funding projects that were completed before June 14, 2016. We chose 23 reward-based crowdfunding projects (involving 27 professional researchers). Two researchers were excluded as the authors could not obtain their contact details online.

General-interest platforms (Readyfor and JapanGiving): the authors selected suitable science crowdfunding projects using three criteria:

(1) The project description included the keywords "kenkȳ" " (research) or "chōsa" (survey). 
(a) Profile of participants

Q1. Do you know "crowdfunding"?

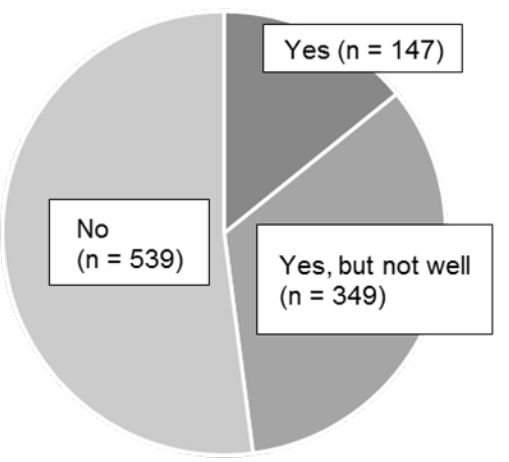

Q3. Have you ever invested in "science crowdfunding"?



(b) Scientific approval process

Q5. What is required when an application is made for funding for a research project?

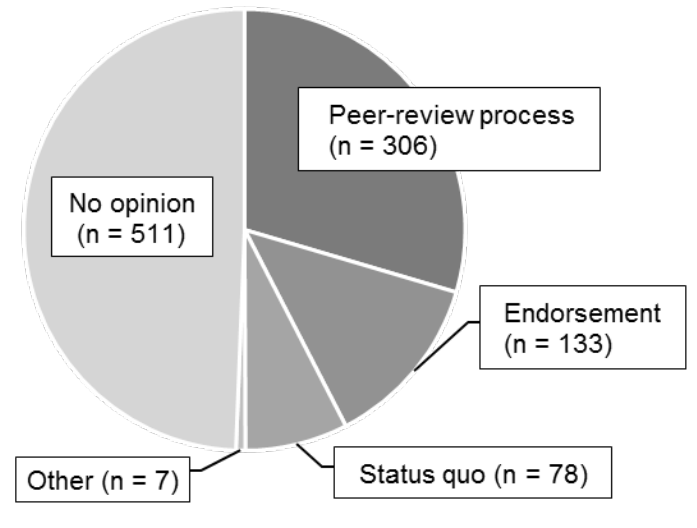

Q2. Do you know "science crowdfunding"?

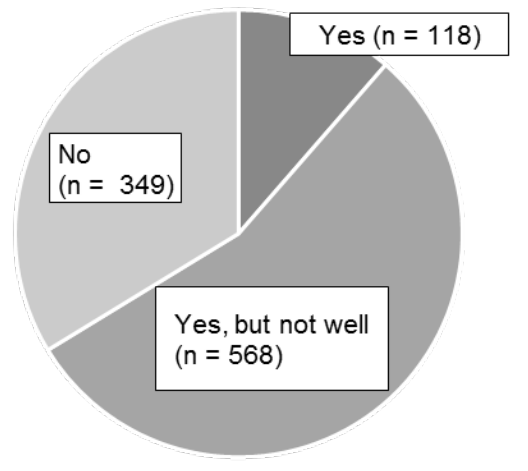

Q4. Are you interested in investing in "science crowdfunding"?

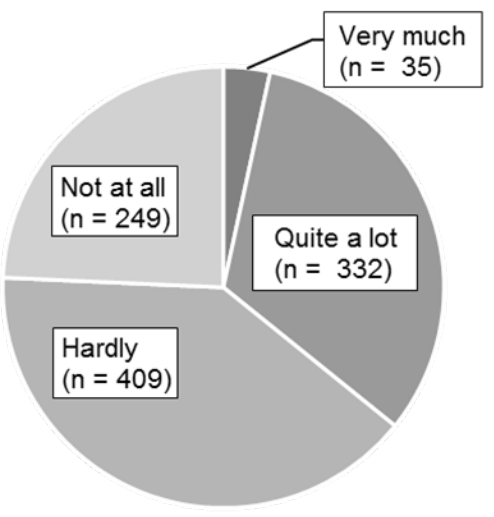

Q6. What is required when research findings are released?



Figure 1. Responses from general public.

(2) The aim of the project is to obtain funding for academic research or institution operating costs. 
(3) The project leader was a professional researcher affiliated with a university or other research institute and had the required qualifications for applying for public research funding via KAKENHI and MEXT.

Criteria (1) and (2) were validated by searching websites and (3) was confirmed by contacting the researchers in question personally. As a result, three reward-based projects (involving three professional researchers) that were completed before August 31, 2016, were selected. All three professional researchers were included in the survey.

A total of 30 professional researchers were sent questionnaires and responses were received from 20 of them (18 on academist, one on Readyfor and one on JapanGiving). Academic crowdfunding is still in its infancy in Japan with few participants, but an important dataset was obtained comprising responses to $66.7 \%$ of the questionnaires sent out. Each questionnaire consisted of 6 questions comparing public research funding and science crowdfunding (Q1 to Q3, Figure 2) and the system of science crowdfunding (Q4 to Q6, Figure 2). We asked the professional researchers taking part whether the current system is adequate or not.

Results

Profile of participants: over $80 \%$ of professional researchers participating had prior experience with research funding, such as a Grant-in-Aid for Scientific Research (Q1 in Figure 2). Of these researchers, $85.0 \%(n=17)$ had successfully applied for funding as principal investigator, $5.0 \%(n=1)$ had unsuccessfully applied for funding as principal investigator, while $10.0 \%(n=2)$ had not applied for funding as principal investigator.

Difference between public funding and science crowdfunding: opinion was divided among the professional researchers on the relative difficulty of raising research funding from public sources compared to academic crowdfunding (Q2 in Figure 2). Of these researchers, $35.0 \%(n=6)$ responded that it was more difficult to prepare an application for crowdfunding, $35.0 \%(n=6)$ felt that the difference in project content meant that the two could not be directly compared, $24.0 \%(\mathrm{n}=4)$ felt that they were of equal difficulty, and $6.0 \%(n=1)$ felt that it was more difficult to prepare an application for public funding. Reasons given in free-text answers for academic crowdfunding being harder included not being accustomed to the tasks required of researchers applying for crowdfunding, the large workload required, the need to respond rapidly to backers, and concern over increased potential exposure. Reasons given in free-text answers for public research funding being harder included the increased difficulty of the research topic itself, the time taken to complete the application, and the increased need for professional skills. These answers suggest that the applicants saw the two processes quite differently.

Professional researchers tended to feel a greater weight of responsibility when engaging in academic crowdfunding rather than applying for public research funds (Q3 in Figure 2). Again, reasons given in free-text answers by researchers indicated that they felt an increased responsibility when engaged in academic crowdfunding due to the closer relationship between researchers and backers, in contrast to public 
(a) Profile of participants

Q1. Have you ever submitted an application for public/private research funds?

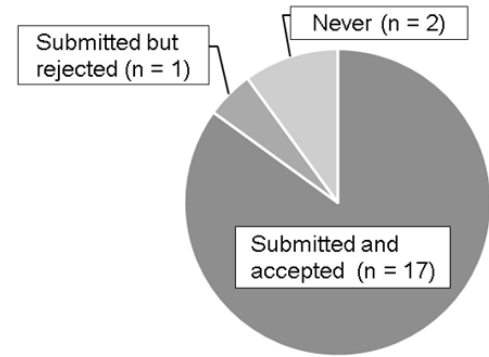

Q2. Was it harder to obtain public research funds or science crowdfunding if you tried to obtain the target amount you set for academic crowdfunding?



Q3. For which do you feel a greater responsibility for science crowdfunding or public research funds?

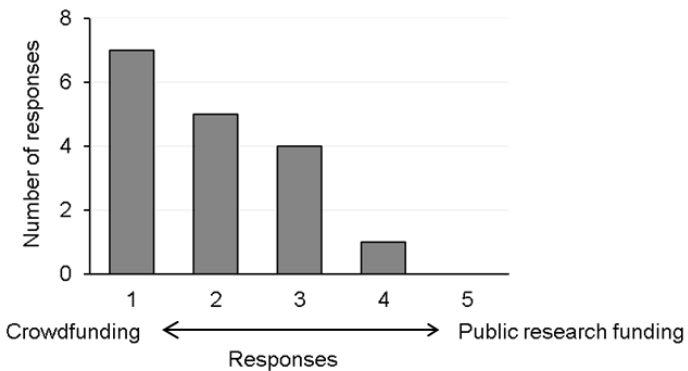

(b) Scientific approval process

Q4. A peer review system overseen by experts is necessary in standard science. However, such peer review process is absent from the science crowdfunding system. Do you think an additional system is necessary in the process of science crowdfunding?
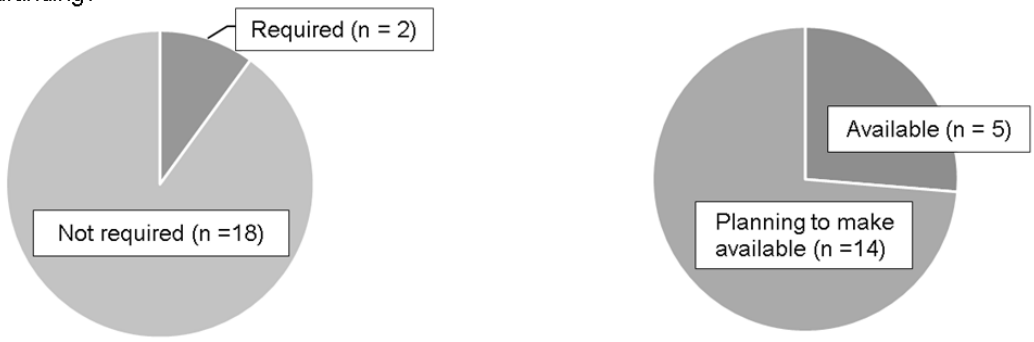

Q6. How did/do you intend to make your findings available?



Figure 2. Responses from professional researchers. 
research funding. Researchers who felt a greater responsibility when engaged in publicly funded research highlighted the greater amount of money involved and the use of donated funds in crowdfunded research, in contrast with the allocation of public funds for publicly funded research.

Lack of any peer review process in science crowdfunding: of these researchers, $90.0 \%(\mathrm{n}=18)$ answered that a peer review process was not necessary as part of the project adoption process, while just $10.0 \%(n=2)$ answered that it was better to include peer review (Q4 in Figure 2). Reasons offered for peer review being unnecessary included the concern that its inclusion might reduce the originality of research projects, that interesting projects might not be adopted, that projects similar to those funded from public sources were more likely to be adopted, and that prejudice and bias might also affect which projects were approved. In addition, it was suggested that the platform administrator effectively performed a similar function to peer review and that it was not necessary to include peer review in a process where members of the public supported projects of their own choosing. Reasons offered in support of including peer review as part of the academic crowdfunding process included improved project quality and preventing the possible funding of pseudoscience. These results suggest that most researchers recognized that academic crowdfunded research projects differed from those funded from public sources.

In addition, about $90 \%$ of the professional researchers approached in this study had already succeeded in obtaining crowdfunding for a previous research project. All of them had either made their research results public in some way or planned to do so (Q5 and Q6 in Figure 2). Of these researchers, 26.3\% $(n=5)$ had made their research results public, $73.7 \%(\mathrm{n}=14)$ intended to do so, and $0 \%$ had no plans to make their research results public. Preferred means of publicising research, based the number of answers given, were presentation at an academic conference or seminar, at a public lecture or cafe scientifique, in print through newspapers or scientific publications, and on the crowdfunding platform itself. Peer-reviewed or non-peer-reviewed journals and reports published by public organizations were unlikely to be selected. Overall, this suggests that the respondents considered it essential to make the results of their research available not only to their respective academic community, via conferences and peer-reviewed journals, but also to the general public.

In this study, $30 \%$ of the general public feel that some form of peer review process, carried out by the Budget-funding Community, is necessary in science crowdfunding. This suggests that at least a part of the general public consider that peer review by the academic community is required. The answer to research question 1 is thus "yes". In contrast, the answer to Research question 2 is "no". Only $10 \%$ of professional researchers who made use of science crowdfunding answered that a peer review process carried out by the Budget-funding Community is necessary in science crowdfunding. They considered that peer review is likely to prevent some "interesting" research topics being pursued. This difference suggests that there is a different view between the general public and professional researchers.

Our investigation of how the general public and professional researchers view science crowdfunding based on the framework of the peer review process revealed 
three issues. First, crowdfunded projects do not pass through a general peer review process by the Budget-funding Community, as we propose to describe the community conducting the peer review process. Second, $30 \%$ of the general public considered that a peer-review process was required in science crowdfunding. Such public anxiety may stem from concern over research misconduct and fake science because of the recent increased disclosure of cases of research misconduct in Japan. Crowdfunding platforms should make efforts to use peer-review like processes to relieve public anxiety. Third, science crowdfunding has the potential to lead to a new type of science, "crowd-supported science".

The research outcomes from science crowdfunding are not limited to returns. Some platforms encourage or require professional researchers to write a brief report on projects for their backers. Experiment.com (U.S.A.) provides researchers with "lab notes" - an online project page where researchers can write progress reports. Experiment.com also provides "The Journal of Results" — an original online journal that can be used for publishing results. ${ }^{9}$ Similarly, academist (Japan) has the "academist journal" - a blog used to publicize results. ${ }^{10}$ These online platform journals can be easily accessed and read by the project backers. However, professional researchers, especially in natural science fields, are evaluated mainly by the number and quality of their peer-reviewed published papers. Thus, they are likely to publicize their results not only in the platforms' journals but also in peer-reviewed papers reviewed by the Journal Community [e.g., Experiment.com; Jaffe et al., 2015; Swift and Marzluff, 2015; academist; Enoto et al., 2017; Okanishi et al., 2017].

Science crowdfunding is supported by many backers via the Internet. We can refer to the aggregation of those backers as a Crowd Community. Each backer in a Crowd Community can individually decide whether or not to financially support a given project. The criteria they use to decide whether to back a project or not (e.g., whether or not it is interesting) may be different from those of a Budget-funding Community consisting entirely of peers.

Science crowdfunding gives rise to "crowd-supported science". This is science that the public supports not only financially but through other means such as tweeting about projects or giving supportive comments on other social media. Projects attractive to the general public are more likely to be supported by people beyond a specific scientific community and contribute to the development of science. The diversity of science proposals is a very important feature of science crowdfunding, but there is the possibility that fake science projects are proposed not only by nonprofessional but also by professional researchers in bad faith.

In normal science, each journal community decides the boundary that separates "science" and "non-journal science" [Fujigaki, 2003]. "Non-journal science" is science but not suitable for publication in academic journals. Peer-review processes contribute to exclude not only "non-journal science" but also "fake science" from the scientific literature. We consider that using a gentle peer review process will contribute to excluding fake science projects in science crowdfunding and maintaining research integrity.

\footnotetext{
${ }^{9}$ Project results of Experiment.com, https:/ / experiment.com/journal, accessed on 1 January 2018.

${ }^{10}$ Official webpage of academist journal, https://academist-cf.com/journal/, accessed on 1 January 2018.
} 
There were a number of limitations affecting this study. First was the limited number of responses from professional researchers. We only received responses from 20 professional researchers. In Japan, only a few professional researchers have made use of science crowdfunding, and we collected responses from as many of these researchers as possible. Although the research-purpose only platform academist is starting to encourage young professional researchers to attempt science crowdfunding, science crowdfunding is an early stage in Japan. It will be important to collect more data in the future. The second limitation was that the study was limited to those respondents able to effectively make use of the Internet. Those who could not use the Internet were not included in our study. This may have produced a bias in the data collected. However, since crowdfunding is, by definition, carried out through the Internet, we consider that online data collection was justified. Third, while this study focused on the natural sciences, not all other academic areas evaluate professional researchers by means of peer review processes. For example, the publication of books (not reviewed by the Journal Community) tends to be highly regarded in some areas of the Humanities. In the normal peer review process, only professional researchers review research projects. However, some researchers in the social sciences, and technology and society, have suggested an alternative in the form of "extended peer review" [Fuller, 2002]. In extended peer review, not only professional researchers but also members of the public participate in the review process. This enables the project to be reviewed from various different perspectives. Fuller [2002] noted that academic and non-academic players often may not be reciprocally accountable. However, Kihara [2003] insisted that the public should be included in any peer review system, especially when reviewing research projects related to public decision-making. If the "gentle peer review" process is implemented in science crowdfunding, the idea of an extended peer review system may also be adopted at some point.

We suggest that crowdfunding functions as a system for involving citizens in science, because citizens financially support science that they want to see carried out. As such, this means that science crowdfunding can enhance public engagement in science. We suggest that scientists' upstream engagement with the public at the funding stage offers greater opportunities to reflect public opinion in the scientific process. To ensure continuing public interest in such direct forms of funding science, researchers taking part in science crowdfunding need to make efforts to maintain research integrity at the high levels maintained by scientific community as a whole.

Funding statement This work was funded by a Kakiuchi Yoshinobu Memorial Award for research from the Japanese Society for Science and Technology Studies presented in 2015 to Hiromi Yokoyama, and supported by World Premier International Research Center Initiative (WPI), MEXT, Japan.

References

Burnham, J. C. (1990). 'The evolution of editorial peer review'. JAMA: The Journal of the American Medical Association 263 (10), pp. 1323-1329. https://doi.org/10.1001/jama.1990.03440100023003.

Byrnes, J. E. K., Ranganathan, J., Walker, B. L. E. and Faulkes, Z. (2014). ‘To crowdfund research, scientists must build an audience for their work'. PloS ONE 9 (12), e110329. https://doi.org/10.1371/journal . pone. 0110329. 
Dahlhausen, K., Krebs, B. L., Watters, J. V. and Ganz, H. H. (2016). ‘Crowdfunding campaigns help researchers launch projects and generate outreach'. Journal of Microbiology \& Biology Education 17 (1), pp. 32-37. https://doi.org/10.1128/jmbe.v17i1.1051.

Enoto, T., Wada, Y., Furuta, Y., Nakazawa, K., Yuasa, T., Okuda, K., Makishima, K., Sato, M., Sato, Y., Nakano, T., Umemoto, D. and Tsuchiya, H. (2017). 'Photonuclear reactions triggered by lightning discharge'. Nature 551, pp. 481-484. https://doi.org/10.1038/nature24630.

Fujigaki, Y. (2003). The public ethic and the spirit of specialism. (in Japanese). Tokyo, Japan: University of Tokyo Press.

Fuller, S. (2002). Knowledge management foundations. Woburn, MA, U.S.A.: Butterworth-Heinemann. https://doi.org/10.1016/B978-0-7506-7365-5.50001-9.

Gieryn, T. F. (1994). 'Boundaries of science'. In: Handbook of science and technology studies. Ed. by S. Jasanoff, G. E. Markle, J. C. Peterson and T. Pinch. Thousand Oaks, CA, U.S.A.: Sage, pp. 393-443. https://doi.org/10.4135/9781412990127.n18.

House of Commons Science and Technology Committee (2011). Peer review in science publications: eight report on session 2010-12. London, U.K.: The Stationery Office. URL: https ://publications . parliament.uk/pa/cm201012/c mselect/cmsctech/856/856.pdf (visited on 1st January 2018).

Hui, J. S. and Gerber, E. M. (2015). 'Crowdfunding science: sharing research with an extended audience'. In: Proceedings of the 18th ACM conference on Computer Supported Cooperative Work E social computing - CSCW '15. New York, NY, U.S.A.: ACM Press, pp. 31-43. https://doi .org/10.1145/2675133. 2675188.

Hui, J. S., Greenberg, M. D. and Gerber, E. M. (2014). 'Understanding the role of community in crowdfunding work'. In: Proceedings of the 17th ACM conference on Computer Supported Cooperative Work \& social computing - CSCW'14. New York, NY, U.S.A.: ACM Press, pp. 62-74. https://doi.org/10.1145/2531602.2531715.

Iseda, T. (2017). 'Social epistemology of research misconducts and peer review'. (in Japanese). Journal of Science and Technology Studies 14, pp. 49-62.

Jaffe, D., Putz, J., Hof, G., Hof, G., Hee, J., Lommers-Johnson, D. A., Gabela, F., Fry, J. L., Ayres, B., Kelp, M. and Minsk, M. (2015). 'Diesel particulate matter and coal dust from trains in the Columbia River Gorge, Washington State, U.S.A.' Atmospheric Pollution Research 6 (6), pp. 946-952. https://doi.org/10.1016/j.apr.2015.04.004.

Kihara, H. (2003). 'The extension of peer review, how should it or should not be done?' Social Epistemology 17 (1), pp. 65-77. https://doi.org/10.1080/0269112032000114840.

Kronick, D. A. (1990). 'Peer review in 18th-century scientific journalism'. JAMA: The Journal of the American Medical Association 263 (10), pp. 1321-1322. https://doi.org/10.1001/jama.1990.03440100021002.

Longino, H. (1990). Science as social knowledge: values and objectivity in scientific inquiry. Princeton, NJ, U.S.A.: Princeton University Press.

Okanishi, M., Fujita, T., Maekawa, Y. and Sasaki, T. (2017). ‘Non-destructive morphological observations of the fleshy brittle star, Asteronyx loveni using micro-computed tomography (Echinodermata, Ophiuroidea, Euryalida)'. ZooKeys 663, pp.1-19. https://doi.org/10.3897/zookeys.663.11413. 
Ranganathan, J. (2012). Adding a (mild) review process to SciFund - why the change? URL: https://scifundchallenge.org/2012/03/04/adding-a-mild-review-pr ocess-to-scifund-why-the-change/ (visited on 1st January 2018).

Schäfer, M. S., Metag, J., Feustle, J. and Herzog, L. (2016). 'Selling science 2.0: what scientific projects receive crowdfunding online?' Public Understanding of Science 27 (5), pp. 496-514. https://doi .org/10.1177/0963662516668771.

Shibato, R. (2015). 'The challenge of academic crowdfunding platform "academist"'. (in Japanese). Johokanri 57 (10), pp. 709-715. https://doi.org/10.1241/johokanri.57.709.

Swift, K. N. and Marzluff, J. M. (2015). 'Wild American crows gather around their dead to learn about danger'. Animal Behaviour 109, pp. 187-197. https://doi.org/10.1016/j.anbehav.2015.08.021.

Vachelard, J., Gambarra-Soares, T., Augustini, G., Riul, P. and Maracaja-Coutinho, V. (2016). 'A guide to scientific crowdfunding'. PLOS Biology 14 (2), e1002373. https://doi.org/10.1371/journal. pbio. 1002373.

Verhoeven, D. and Astheimer, L. (2013). 'Short on grant money? Five tips for crowdfunding success'. The Conversation, pp. 1-4.

Weigmann, K. (2013). 'Tapping the crowds for research funding'. EMBO reports 14 (12), pp. 1043-1046. https://doi.org/10.1038/embor.2013.180.

Wellcome Trust (2015). 'Scholarly communication and peer review. The current landscape and future trends'. URL: https://wellcome.ac.uk/sites/default/f iles/scholarly-communication-and-peer-review-mar15.pdf (visited on 1st January 2018).

Wheat, R. E., Wang, Y., Byrnes, J. E. and Ranganathan, J. (2013). 'Raising money for scientific research through crowdfunding'. Trends in Ecology \& Evolution 28 (2), pp. 71-72. https://doi.org/10.1016/j.tree.2012.11.001.

Authors

Yuko Ikkatai is a project researcher at the Kavli Institute for the Physics and Mathematics of the Universe, the University of Tokyo. Her research interests are science communication, citizen science and animal psychology.

E-mail: y.ikkatai@gmail.com.

Euan McKay is project assistant professor at the Division for Strategic Public Relations, the University of Tokyo. His research interests are communication, diversity and history. E-mail: euan.mckay@mail.u-tokyo.ac.jp.

Hiromi M. Yokoyama is professor at the Kavli Institute for the Physics and Mathematics of the Universe, the University of Tokyo. Her research interests are science communication and public policy. E-mail: hiromi.yokoyama@ipmu.jp.

\section{How to cite}

Ikkatai, Y., McKay, E. and Yokoyama, H. M. (2018). 'Science created by crowds: a case study of science crowdfunding in Japan'. JCOM 17 (03), A06.

https://doi.org/10.22323/2.17030206.

(C) The Author(s). This article is licensed under the terms of the Creative Commons Attribution - NonCommercial - NoDerivativeWorks 4.0 License. ISSN 1824-2049. Published by SISSA Medialab. jcom.sissa.it 